\title{
Study of the pedigree of a patient with type III hyperlipoproteinaemia and sinking prebeta lipoprotein
}

\author{
D. BALlANTYNE ${ }^{1}$, JANET S. JUBB, H. G. MORGAN, AND T. D. V. LAWRIE \\ From the Department of Medical Cardiology and of Clinical Biochemistry, Glasgow Royal Infirmary
}

SYNOPSIS A 49-year-old woman, suffering from peripheral vascular disease, was found to have two lipoprotein abnormalities, namely, type III hyperlipoproteinaemia and sinking prebeta lipoprotein. Twenty-one members of the kindred were investigated in an attempt to determine the pattern of inheritance of both of these abnormalities.

In a 21-year-old son of the proband plasma electrophoresis was in keeping with a type $\mathrm{V}$ hyperlipoproteinaemia. It is suggested that this may be a stage in the development of the characteristic type III pattern. If this is so it is consistent with previous suggestions of an incompletely penetrant single autosomal allele. Sinking prebeta lipoprotein was found in the plasma of two other members of the family. If this abnormality is also inherited as a single autosomal allele it must have a very low penetrance and the possibility that the abnormality is acquired cannot be excluded.

The pattern of plasma lipoproteins has become a useful method of classification of disorders in lipid metabolism. Five types have been defined on the basis of paper electrophoresis of plasma (Fredrickson, Levy, and Lees, 1967).

Prebeta lipoproteins are usually considered synonymous with very low density lipoproteins (VLDL) floating on ultracentrifugation at $\mathrm{D}=$ $1.006(\mathrm{D}=$ density $)$. Recent studies, however, have demonstrated a significant prevalence of prebeta material that sediments at $D=1 \cdot 006$. This has been name sinking pre-beta lipoprotein (Rider, Levy, and Fredrickson, 1970; Ellefson, Jiminez, and Smith, 1971).

In type III hyperlipoproteinaemia electrophoresis of supernatant and infranatant obtained by ultracentrifugation demonstrates the presence of beta migrating material in the fraction $D<1.006$. This is often associated with a variable rise in total cholesterol and triglyceride concentrations. In addition, there is often an increase in the prebeta band which is chemically normal, that is, it corresponds to very low density lipoprotein and floats at $\mathrm{D}=1.006$.

This report describes a patient with type III hyperlipoproteinaemia and sinking prebeta lipo-

${ }^{1}$ Requests for reprints to Dr D. Ballantyne, Department of Medical Cardiology, Royal Infirmary, Glasgow G4 OSF.

Received for publication 28 December 1972. protein. The patient was a member of a large family, which was also investigated in an attempt to determine the mode of inheritance of these abnormalities.

\section{Case Reports}

A 49-year-old woman presented with a 10-month history of intermittent claudication affecting her right calf. She was moderately overweight and all pulses were absent in the right leg. There were no xanthomas. Blood pressure was 130/80. There was no evidence of cardiac disease. An ECG was normal. The aortogram revealed a block of the right common iliac artery. Disorders such as diabetes mellitus, the nephrotic syndrome and hypothyroidism, which are known to be associated with the hyperlipoproteinaemias, were excluded. There was no glycosuria or proteinuria, fasting plasma glucose concentration was $75 \mathrm{mg} / 100 \mathrm{ml}$, uric acid $4.8 \mathrm{mg} / 100 \mathrm{ml},{ }^{127} \mathrm{PBI}$ $6 \cdot 1 \mu \mathrm{g} / 100 \mathrm{ml}$. Creatinine clearance was $85 \mathrm{ml} / \mathrm{min}$.

\section{PEDIGREE}

Lipoprotein typing, as described below, was carried out in 21 members of the family in three generations. The presence or absence of vascular disease was noted. The spouses of a niece and nephew of the proband were also investigated.

\section{Methods}

A sample of venous blood $(35 \mathrm{ml})$ was withdrawn 
from each subject after an overnight fast. Total plasma cholesterol concentration was estimated by the method of Annan and Isherwood (1967), and plasma triglyceride concentration obtained as described by Kessler and Lederer (1965). Five $\mathrm{ml}$ of plasma was then spun at $D=1.006$ in a Spinco model L ultracentrifuge for 16 hours at $100000 \mathrm{~g}$. The tubes were sliced and the supernatant $(D<$ $1.006)$ and infranatant $(D>1.006)$ were obtained. The concentration of cholesterol in these fractions was measured and from the infranatant low density lipoprotein (LDL) was precipitated with heparin/ $\mathrm{MnCl}_{2}$ (Burstein, Scholmnick, and Morfin, 1970). From these data the cholesterol values for low density lipoprotein (LDL) and very low density lipoprotein (VLDL) were calculated. Paper electrophoresis of whole plasma, supernatant, and infranatant was carried out using albuminated buffer (Lees and Hatch, 1964).

\section{Results}

\section{STUDY OF THE PROBAND}

Lipoprotein analysis was performed on three separate fasting blood samples taken several weeks apart. The values obtained are shown in table $I$. Electrophoresis of the supernatant $(D<1.006)$ and infranatant $(D>1.006)$ was carried out on each of the three specimens and gave identical patterns (fig 1). On electrophoresis of whole plasma a diffuse beta and an increased prebeta band were found. The former was present in the density fraction $D<1.006$ (type III pattern) and the latter in the density fraction $D>1.006$ (sinking prebeta).

\begin{tabular}{|c|c|c|c|c|c|}
\hline \multirow{2}{*}{$\begin{array}{l}\text { Sample } \\
\text { No. }\end{array}$} & \multicolumn{4}{|c|}{ Cholesterol Concentration (mg $100 \mathrm{ml}$ ) } & \multirow{2}{*}{$\begin{array}{l}\text { Plasma } \\
\text { Triglycerides } \\
\text { (mg } 100 \mathrm{ml})\end{array}$} \\
\hline & Plasma & $V L D L$ & $L D L$ & $H D L$ & \\
\hline $\begin{array}{l}1 \\
2 \\
3\end{array}$ & $\begin{array}{l}330 \\
275 \\
395\end{array}$ & $\begin{array}{r}120 \\
85 \\
110\end{array}$ & $\begin{array}{l}158 \\
141 \\
227\end{array}$ & $\begin{array}{l}52 \\
49 \\
58\end{array}$ & $\begin{array}{l}211 \\
213 \\
385\end{array}$ \\
\hline
\end{tabular}

Table I Findings in the proband

STUDIES OF THE KINDRED

Each member of the kindred shown in fig. 2 was investigated and the results tabulated (table II). One member of the pedigree (III-1) aged 21 years, had hypertriglyceridaemia with increased prebeta lipo-

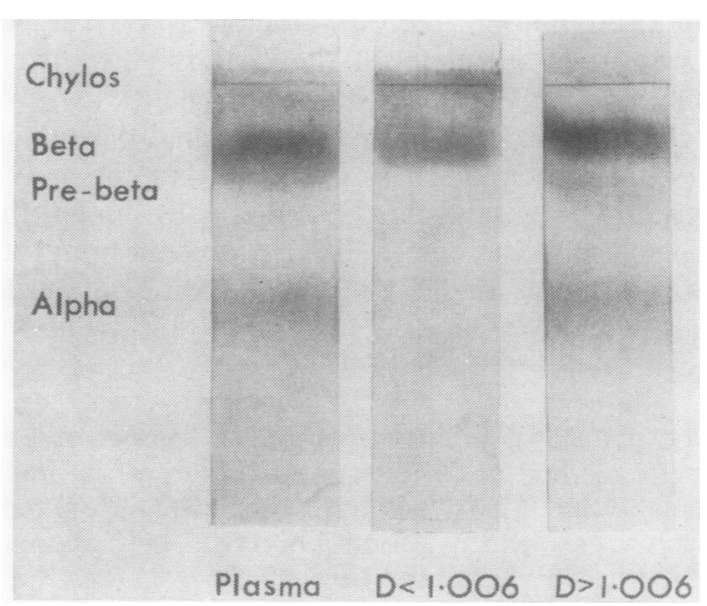

Fig 1 Electrophoresis of plasma and density fractions $D<1.006$ and $D>1.006$ in the proband.

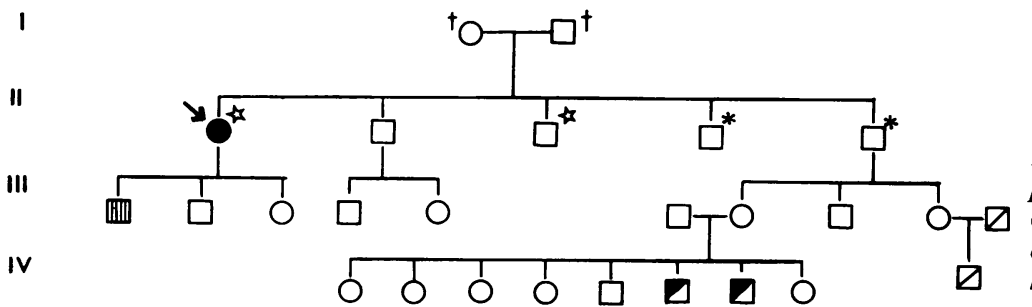

Fig 2 Family pedigree *Type $V$ pattern on plasma electrophoresis. Other features (see text) were not consistent with a primary type $V$ hyperlipoproteinaemia. 


\begin{tabular}{|c|c|c|c|c|c|c|c|c|c|c|c|}
\hline \multirow[t]{2}{*}{ Sex } & \multirow[t]{2}{*}{ Age } & \multirow[t]{2}{*}{$\begin{array}{l}\text { Pedigree } \\
\text { Position }\end{array}$} & \multirow[t]{2}{*}{$\begin{array}{l}\text { Vascular } \\
\text { Disease }\end{array}$} & \multirow{2}{*}{$\begin{array}{l}\text { Plasma } \\
\text { Triglycerides } \\
(\mathrm{mg} / 100 \mathrm{ml})\end{array}$} & \multicolumn{4}{|c|}{$\begin{array}{l}\text { Cholesterol Concentration } \\
(\mathrm{mg} / 100 \mathrm{ml})\end{array}$} & \multicolumn{3}{|c|}{$\begin{array}{l}\text { Lipoprotein Abnormalities on Paper } \\
\text { Electrophoresis }\end{array}$} \\
\hline & & & & & Plasma & $V L D L$ & $L D L$ & $H D L$ & Whole Plasma & $D>1.006$ & $D>1.006$ \\
\hline $\mathbf{F}$ & 49 & II-1 & PVD & See table I & & & & & Diffuse beta & Beta & Prebeta \\
\hline $\mathbf{M}$ & 54 & II-2 & - & 183 & 255 & 30 & 198 & 27 & $\mathbf{N}$ & $\mathbf{N}$ & $\mathbf{N}$ \\
\hline $\mathbf{M}$ & 52 & II-3 & PVD & 88 & 235 & 20 & 168 & 37 & $\mathbf{N}$ & $\mathbf{N}$ & $\mathbf{N}$ \\
\hline $\mathbf{M}$ & 56 & II-4 & CHD & 124 & 205 & 25 & 138 & 42 & $\mathbf{N}$ & - & - \\
\hline $\mathbf{M}$ & 70 & II-5 & CHD & 135 & 200 & 30 & 132 & 38 & $\mathbf{N}$ & $\mathbf{N}$ & $\mathbf{N}$ \\
\hline $\mathbf{M}$ & 21 & III-1 & - & 295 & 223 & 50 & 138 & 37 & Chylomicrons & Chylomicrons & \\
\hline & & & & 325 & 220 & 45 & 130 & 45 & $+\uparrow$ prebeta & $+\uparrow$ prebeta & \\
\hline $\mathbf{M}$ & 15 & III-2 & - & 38 & 150 & 5 & 98 & 47 & $\mathbf{N}$ & $\mathbf{N}$ & $\mathbf{N}$ \\
\hline $\mathbf{F}$ & 17 & III-3 & - & 128 & 190 & 20 & 148 & 22 & $\mathbf{N}$ & $\mathbf{N}$ & $\mathbf{N}$ \\
\hline $\mathbf{M}$ & 11 & III -4 & - & 70 & 205 & 10 & 174 & 21 & $\mathbf{N}$ & $\mathbf{N}$ & $\mathbf{N}$ \\
\hline $\mathbf{F}$ & 13 & III-5 & - & 55 & 165 & 15 & 103 & 47 & $\mathbf{N}$ & $\mathbf{N}$ & $\mathbf{N}$ \\
\hline $\mathbf{M}^{1}$ & 45 & III-6 & - & 100 & 180 & - & - & - & $\mathbf{N}$ & & \\
\hline $\mathbf{F}$ & 44 & III-7 & - & 158 & 190 & 20 & 122 & 45 & $\mathbf{N}$ & $\mathbf{N}$ & $\mathbf{N}$ \\
\hline $\mathbf{M}$ & 47 & III-8 & - & 118 & 225 & 25 & 158 & 42 & $\mathbf{N}$ & $\mathbf{N}$ & $\mathbf{N}$ \\
\hline $\mathbf{F}$ & 42 & III-9 & - & 115 & 260 & 10 & 192 & 58 & $\mathbf{N}$ & $\mathbf{N}$ & $\mathbf{N}$ \\
\hline $\mathbf{M}$ & 43 & III-10 & - & 375 & 220 & 55 & 139 & 26 & $\uparrow$ Prebeta & $\uparrow$ Prebeta & $\mathbf{N}$ \\
\hline $\mathbf{F}$ & 13 & IV-1 & - & 80 & 155 & 5 & 112 & 38 & $\mathbf{N}$ & $\mathbf{N}$ & $\mathbf{N}$ \\
\hline $\mathbf{F}$ & 18 & IV-2 & - & 100 & 280 & 25 & 181 & 74 & $\mathbf{N}$ & $\mathbf{N}$ & $\mathbf{N}$ \\
\hline $\mathbf{F}$ & 18 & IV-3 & - & 45 & 145 & 15 & 77 & 53 & $\mathbf{N}$ & $\mathbf{N}$ & $\mathbf{N}$ \\
\hline $\mathbf{F}$ & 11 & IV -4 & - & 120 & 200 & 10 & 93 & 47 & $\mathbf{N}$ & $\mathbf{M}$ & $\mathbf{N}$ \\
\hline $\mathbf{M}$ & 27 & IV-5 & - & 70 & 190 & 30 & 117 & 53 & $\mathbf{N}$ & $\mathbf{N}$ & $\mathbf{N}$ \\
\hline $\mathbf{M}$ & 25 & IV-6 & - & 95 & 220 & 35 & 132 & 53 & $\mathbf{N}$ & $\mathbf{N}$ & Prebeta \\
\hline $\mathbf{M}$ & 22 & IV-7 & - & 153 & 230 & 25 & 159 & 46 & $\mathbf{N}$ & $\mathbf{N}$ & Prebeta \\
\hline $\mathbf{F}$ & 15 & IV-8 & - & 70 & 165 & 15 & 108 & 42 & $\mathbf{N}$ & $\mathbf{N}$ & $\mathbf{N}$ \\
\hline $\mathbf{M}$ & 10 & IV-9 & - & 270 & 227 & 45 & 132 & 32 & $\uparrow$ Prebeta & $\uparrow$ Prebeta & $\mathbf{N}$ \\
\hline
\end{tabular}

Table II Findings in the kindred

1 = insufficient plasma for ultracentrifugation

$\mathbf{N}=$ normal

PVD = peripheral vascular disease

CHD = coronary heart disease

protein and chylomicrons on plasma electrophoresis. Both of these lipoproteins were present in the fraction $\mathrm{D}<1.006$. A month later a further fasting plasma sample was withdrawn and similar results were obtained. In neither sample was there beta migrating lipoprotein of $\mathrm{D}<1.006$ or prebeta material of $D>1.006$. Although the lipoprotein pattern obtained on electrophoresis of plasma and the ultracentrifugal fractions were in keeping with a type V hyperlipoproteinaemia, the total plasma cholesterol and triglyceride concentrations, age, and clinical features were not consistent with a primary type $\mathrm{V}$ hyperlipoproteinaemia.

Two members of the pedigree (IV-6 and IV-7) had sinking prebeta lipoprotein in their plasma. Since no member with sinking prebeta was found in generation III, both parents (III-5, III-6) of those affected in generation IV were studied, but no abnormality was found. In one of the parents (III-6), although there was insufficient plasma for ultracentrifugation, no prebeta band was detected on electrophoresis of whole plasma. One member of generation IV (IV-9) had a type IV hyperlipoproteinaemia. Both parents (III-9 and III-10) were studied and a type IV hyperlipoproteinaemia was found in the father (III-10).

\section{Discussion}

Type III hyperlipoproteinaemia is associated with premature vascular disease, especially of peripheral vessels though the frequency of such involvement is not the same in reported studies (Fredrickson and Levy, 1971; Borrie, 1969). In the absence of disease with which the hyperlipoproteinaemias are associated the diagnosis of the phenotype is made by lipoprotein analysis. The definitive test is ultracentrifugal separation with electrophoresis of supernatant and infranatant. This demonstrates that the beta migrating material present on electrophoresis of whole plasma floats at a density $D=1.006$ after ultracentrifugation. In its untreated state type III hyperlipoproteinaemia is always associated with the presence in plasma of increased amounts of prebeta lipoprotein, which is chemically normal and floats at D $<1.006$ (Fredrickson, 1971).

The current case is an exception, since, although the prebeta lipoprotein concentration of whole plasma was increased, the combination of paper electrophoresis and ultracentrifugation demonstrated that this lipoprotein fraction was found in the infranatant $(D>1.006)$. This has been named sinking prebeta lipoprotein, and has been reported 
as occurring in about $10 \%$ of all lipoprotein analyses (Rider et al, 1970; Ellefson et al, 1971). Inheritance of this disorder is thought to be through a single autosomal allele. At present it is not considered to be associated with an increased incidence of vascular disease (Rider et al, 1970).

The pattern of inheritance of type III hyperlipoproteinaemia is uncertain. Fredrickson and Levy (1971) found vertical transmission in five of 36 families and suggested an incompletely penetrant dominant mode.

The patient described here has therefore two lipoprotein abnormalities, viz, type III hyperlipoproteinaemia and sinking prebeta lipoprotein. This combination does not appear to have been reported previously. Since these lipoprotein abnormalities are considered to have different modes of inheritance the pedigree of this patient was investigated.

One member, a son of the proband, had chylomicrons and increased prebeta lipoprotein on plasma electrophoresis, but no beta lipoprotein of $\mathrm{D}<1.006$. Although these findings were in keeping with a type $\mathrm{V}$ pattern, it is unlikely that he has a primary type $\mathrm{V}$ hyperlipoproteinaemia (see above). Since his mother (the proband) has a type III hyperlipoproteinaemia the abnormalities found in her son may represent a stage in the development of the characteristic type III pattern. Coronary heart disease was present in two siblings of the proband and peripheral vascular disease occurred in another without evidence of an associated lipoprotein abnormality. This may suggest either an increased risk of atherosclerosis in relatives of patients with type III hyperlipoproteinaemia, whether or not they have inherited the lipoprotein abnormality, or that they have a disorder of lipid metabolism which present methods of lipoprotein analysis do not detect.

It has been suggested that there is a relationship between type III and type IV hyperlipoproteinaemias, and a family with members showing both types III and IV hyperlipoproteinaemia has recently been described (Matthews, 1968). However, the type III classification was based solely on the presence of increases in both serum triglycerides and cholesterol and further diagnostic procedures such as determination of the lipid composition and electrophoretic mobility of the fraction of density $D<1.006$ were not performed. One member of the kindred studied here (IV-9; aged 10 years) was found to have a type IV hyperlipoproteinaemia. However, his father, not a member of the kindred, was also affected and it seems likely that he is the source of the abnormality in this child. Therefore, we have not found any evidence to support the view that there is an association between the inheritance of types III and IV hyperlipoproteinaemia.

Two subjects (IV-6 and IV-7) were found to have sinking prebeta lipoprotein. Apart from the proband no other member of the pedigree had this abnormality If sinking prebeta lipoprotein is inherited as a single autosomal allele it must have a very low penetrance and from the kindred described here the possibility that the abnormality is acquired cannot be excluded. It is significant that the two relatives of the proband in this family, who had sinking prebeta lipoprotein in plasma, had normal total plasma triglyceride and cholesterol concentrations and electrophoreticseparation. Where ultracentrifugation and electrophoresis of supernatant and infranatant are not carried out routinely this abnormality will be missed.

We thank Dr F. C. Cox, Dr A. R. Lorimer, and Dr M. A. Ferguson-Smith for their advice and criticism.

References

Annan, W., and Isherwood, D. M. (1967). An automated method for the direct determination of total serum cholesterol. $J$. med. Lab. Technol., 26, 202-211.

Borrie, P. (1969). Type III Hyperlipoproteinaemia. Brit. med. J., 2, 665-667.

Burstein, M., Scholmnick, H. R., and Morfin, R. (1970). Rapid method for the isolation of lipoproteins from human serum by precipitation with polyanions. J. Lipid Res., 11, 583-595.

Ellefson, R. D., Jiminez, B. F., and Smith, R. C. (1971). Pre-beta (or $\alpha_{2}$ ) lipoprotein of high density in human blood. Mayo Clin. Proc., 46, 328-332.

Fredrickson, D. S., and Levy, R. I. (1972). Familial hyperlipoproteinemia. In The Metabolic Basis of Inherited Disease, edited by J. B. Stanbury, J. B. Wyngaarden, and D. S. Fredrickson, 3rd ed., pp. 545-614. McGraw-Hill, New York.

Fredrickson, D. S. (1971). Mutants, hyperlipoproteinaemia, and coronary artery disease. Brit. med. J., 2, 187-192.

Fredrickson, D. S., Levy, R. I., and Lees, R. S. (1967). Fat transport in lipoproteins-an integrated approach to mechanisms and disorders. New Engl. J. Med., 276, 34-44, 94-103, 148-156. 215-225, and 273-281.

Kessler, G., and Lederer, H. (1965). Fluorometric measurement of triglycerides. In Automation in Analytical Chemistry (Technicon Symposia), edited by L. T. Speggs, pp. 341-344. Mediad Inc., New York.

Lees, R. S., and Hatch, F. T. (1963). Sharper separation of lipoprotein. species by paper electrophoresis in albumin-containing buffer. J. Lab. clin. Med., 61, 518-528.

Matthews, R. J. (1968). Type III and IV familial hyperlipoproteinemia. Evidence that these two syndromes are different phenotypic expressions of the same mutant gene(s). Amer. J. Med., 44, 188-199.

Rider, A. K., Levy, R. I., and Fredrickson, D. S. (1970). 'Sinking' pre-beta lipoprotein and the Lp antigen. (Abstr.) Circulation. 41-42. Suppl. 3, 10. 